\title{
Aetiology of community-acquired pneumonia: a prospective study among adults requiring admission to hospital
}

\author{
Rob Bohte, Ralph van Furth, Pieter J van den Broek
}

\begin{abstract}
Background - The prevalence of microorganisms causing community-acquired pneumonia in patients who required admission to hospital was investigated and the percentage of cases whose aetiology remained unknown due to the study design and logistical problems estimated.

Methods - Between January 1991 and April 1993 all patients with community-acquired pneumonia admitted to six hospitals were included in the study. Aetiological diagnosis, categorised as definite, probable and possible, was based on the results of routine microbiological and serological tests.
\end{abstract}

Results - Three hundred and thirty four patients with a median age of 65 (range 17-92) years were enrolled in the study. The diagnosis of community-acquired pneumonia was definite in 108 cases, and probable or possible in 73 and 27 cases, respectively, including dual infections. Streptococcus pneumoniae was the predominant pathogen (27\%) followed by viruses and Haemophilus influenzae (both about 8\%) and Mycoplasma pneumoniae (6\%). Chlamydia spp (3\%) and Legionella pneumophila (2\%) were less frequently detected. No diagnosis was made in $45 \%$ of the cases. With adjustment for antimicrobial therapy before admission and for other logistical considerations, it is estimated that the aetiology could have been ascertained in $65 \%$ of the cases.

Conclusions - Streptococcus pneumoniae is the most frequently detected cause of community-acquired pneumonia. The inability to detect a micro-organism results mainly from the use of routine diagnostic tests and, to a lesser extent, from logistical problems or the use of antibiotics before admission.

(Thorax 1995;50:543-547)

Keywords: community-acquired pneumonia, aetiology, adults.

Community-acquired pneumonia is not a notifiable disease so the exact incidence is unknown. Overall estimates of its annual incidence vary from one to four per 1000 population in the UK and the Netherlands, and $5-20 \%$ of these cases are admitted to hospital. ${ }^{12}$ The elderly are at highest risk, with those aged 65 years or older accounting for $70 \%$ of cases in the Netherlands. ${ }^{2}$ Community-acquired pneumonia is the sixth leading cause of death in both the USA and UK. ${ }^{3-5}$ In the Netherlands the case fatality rate for community-acquired pneumonia was $4 \%$ in $1992 .{ }^{6}$ Age-adjusted death rates for pneumonia have declined between 1950 and $1986 .^{7}$ The proportional mortality for pneumonia, however, has remained stable during this period; this can be explained by the rapidly increasing number of persons still alive at 85 years of age.

The infecting micro-organism is usually unknown when antimicrobial therapy for community-acquired pneumonia is started. The results of blood and sputum cultures may not be available for two or three days. Serological tests, in general, are not performed before a second serum sample is taken after two or three weeks. Initial therapy is therefore empirical, based on the clinical picture and the presumed prevalence of the causative pathogen.

Several recent studies on patients with community-acquired pneumonia who required admission to hospital showed considerable differences in frequencies of causative agents, ${ }^{489}$ with seasonal, epidemiological, and geographical factors, as well as the diagnostic methods applied, affecting the results. Apart from the UK, no large studies on the aetiology of community-acquired pneumonia have been performed recently in the European Community.

In this study we investigated prospectively the prevalence of micro-organisms causing community-acquired pneumonia which necessitated admission to hospital. Furthermore, we estimated the percentage of cases whose aetiology remained unknown due to the study design and logistical problems, and compared our results with those of other large studies recently reported.

\section{Methods}

PATIENTS

Between January 1991 and April 1993 all patients with community-acquired pneumonia admitted to the six participating hospitals (one university and five general hospitals) located in an area of 1600 square kilometres around Leiden were included. Community-acquired pneumonia was defined as a new infiltrate on the chest radiograph. Patients with causes other than infection, such as cardiac failure or pulmonary emboli, were excluded on clinical grounds, as were those aged under 18 years, those living in a nursing home, or patients who 
Table 1 Underlying diseases in patients with communityacquired pneumonia $(n=322) *$

\begin{tabular}{lc}
\hline Disease & No. of patients (\%) $\dagger$ \\
\hline Cardiovascular diseases & $138(43)$ \\
Chronic pulmonary disease & $88(27)$ \\
Malignancy & $48(15)$ \\
Neurological diseases & $34(11)$ \\
Renal insufficiency & $23(7)$ \\
Diabetes mellitus & $30(9)$
\end{tabular}

* 12 patients without valid data concerning medical history were excluded.

† Some patients had more than one underlying disease.

had been hospitalised within one week of this admission. All patients were interviewed by the same investigator (RB) who used a standard questionnaire to obtain the medical history.

\section{MICROBIOLOGICAL ASSAYS}

On admission two blood cultures and, if sputum was expectorated, a Gram stain and culture of sputum were performed. No cultures for Legionella spp, Chlamydia spp, or Mycoplasma pneumoniae were performed. Blood samples for serological testing were obtained in the acute stage of illness and after 2-6 weeks of convalescence. Serum samples were tested in pairs. Complement fixation tests were performed for influenza viruses $A$ and $B$, parainfluenza viruses 1,2 and 3, adenovirus, and respiratory syncytial virus. An immunofluorescence antibody test was used to detect antibodies against Legionella pneumophila serogroups 1-14, Coxiella burnetii, and Chlamydia spp. Microbiological assays were performed according to routine procedures at the laboratories of the participating hospitals.

\section{CRITERIA FOR AETIOLOGICAL CLASSIFICATION OF} PNEUMONIA

The agents detected by culture or serology were classified as definite, probable, or possible causes of the community-acquired pneumonia. When no causative agent was found the pneumonia was classified as being of unknown aetiology. A micro-organism was considered the definite cause of community-acquired pneumonia if: (1) it was cultured from blood or pleural fluid, or (2) a fourfold or greater rise in titre in any of the serological tests or a single titre in the acute stage of $\geqslant 1: 256$ in the complement fixation test was detected; probable if: (1) growth of a predominant bacterial pathogen on sputum culture in combination with the sputum Gram stain revealed the same pathogen, or (2) a single titre in serum from a convalescent patient of $\geqslant 1: 128$ in the complement fixation test was obtained; and possible if a predominant bacterial pathogen likely to cause community-acquired pneumonia was grown on sputum culture. Patients in whom more than one micro-organism was detected according to the above criteria suffered from a double infection.

\section{DATA ANALYSIS}

Univariate analysis required cross tabulation and $\chi^{2}$ testing for categorical variables; continuous variables were analysed by Student's $t$ test.

\section{Results \\ PATIENTS}

Three hundred and thirty four patients (195 men, $58 \%$ ) were enrolled in the study, with significantly fewer being enrolled during the summer than during the other seasons $\left(\chi^{2}\right.$, $\mathrm{p}<0.05)$. The median age of the total study population was 65 years with a range of 17-92 years $(95 \%$ of the population was aged between 27 and 85 ). Most patients (61\%) suffered from chronic diseases including cardiovascular diseases (congestive heart failure, hypertension, and myocardial infarction) and pulmonary diseases (chronic bronchitis and emphysema); 53 patients had both (table 1). Lung and breast carcinomas together with haematological malignancies accounted for more than $95 \%$ of coexistent malignancies. Twenty nine patients suffered from neurological diseases caused by cerebrovascular disorders. No medical history was available on 12 patients. Fifty four patients had taken antibiotics prior to admission, amoxycillin being the most frequently prescribed (44\%).

\section{AETIOLOGY}

Blood cultures were taken for all 334 patients, yielding a pathogen in 52 cases (16\%). Gram stain and sputum cultures were performed in

Table 2 Aetiology of community-acquired pneumonia

\begin{tabular}{|c|c|c|c|c|}
\hline \multirow[t]{2}{*}{ Organism } & \multicolumn{4}{|c|}{ Classification of pneumonia } \\
\hline & $\begin{array}{l}\text { Definite } \\
(n=108)\end{array}$ & $\begin{array}{c}\text { Probable } \\
(n=73)\end{array}$ & $\begin{array}{l}\text { Possible } \\
(n=27)\end{array}$ & $\begin{array}{l}\text { Total (\%) } \\
(n=334)\end{array}$ \\
\hline $\begin{array}{l}\text { Streptococcus pneumoniae } \\
\text { Haemophilus influenzae } \\
\text { Mycoplasma pneumoniae } \\
\text { Chlamydia spp } \\
\text { Legionella pneumophila } \\
\text { Streptococcus spp } \\
\text { Other bacteria* } \\
\text { Influenza A/B virus } \\
\text { Parainfluenza } 2 / 3 \text { viruses } \\
\text { Other viruses } \dagger \\
\text { Unknown }\end{array}$ & $\begin{array}{r}44 \\
19 \\
6 \\
5 \\
7 \\
6 \\
12 \\
6 \\
3 \\
-\end{array}$ & $\begin{array}{l}40 \\
14 \\
3 \\
3 \\
1 \\
6 \\
2 \\
2 \\
2 \\
-\end{array}$ & $\begin{array}{l}6 \\
12 \\
= \\
= \\
= \\
= \\
=\end{array}$ & $\begin{aligned} 90 & (27) \\
26 & (8) \\
19 & (6) \\
9 & (3) \\
8 & (2) \\
8 & (2) \\
21 & (6) \\
14 & (4) \\
8 & (2) \\
5 & (1) \\
151 & (45)\end{aligned}$ \\
\hline
\end{tabular}

Patients with dual infections are included.

${ }^{*} M$ catarrhalis (5), $S$ aureus (4, of which 3 definite), $K$ pneumoniae (4, of which 2 definite), $E$ coli (4), $K$ oxytoca (3), $C$ burnetii (1, definite).

† Respiratory syncytial virus (3, all definite) and adenovirus (2). 
Table 3 Dual infection in patients with community-acquired pneumonia

\begin{tabular}{|c|c|c|c|c|}
\hline & Streptococcus spp* & $H$ influenzae & $M$ catarrhalis & Enterobacteriaceae \\
\hline Chlamydia spp & 3 & 1 & - & 1 \\
\hline Parainfluenza 3 virus & 3 & - & - & 1 \\
\hline Influenza $\mathrm{A} / \mathrm{B}$ virus & $4 \dagger$ & - & - & 1 \\
\hline$M$ pneumoniae & 2 & 1 & - & 1 \\
\hline$C$ burnetii & 1 & - & - & - \\
\hline Respiratory syncytial virus & - & 1 & - & - \\
\hline$S$ pneumoniae & - & 2 & 2 & 1 \\
\hline
\end{tabular}

* All but one were $S$ pneumoniae.

† One $S$ milleri.

204 patients $(61 \%)$ who expectorated sputum within 24 hours of admission. Serological tests were performed for 239 patients $(72 \%)$; for the remaining 95 patients serological test results were unknown because a second serum sample was not obtained due to death within two weeks of admission $(n=16)$ or because patients were lost to follow up $(n=79)$. A definite aetiological diagnosis of community-acquired pneumonia was made in 108 cases, and probable and possible aetiological diagnoses in 73 and 27 cases, respectively, including dual infections (table 2). In 151 cases (45\%) the aetiology remained unknown.

Streptococcus pneumoniae accounted for $41 \%$ $(44 / 108)$ of those with a definite aetiology of community-acquired pneumonia, and $M$ pneumoniae (19/108) and viruses (21/108) shared second place with almost $20 \%$. Streptococcus spp (6\%), Chlamydia spp (6\%), and Legionella pneumophila (5\%) were identified less frequently as the definite cause. In three patients Streptococcus milleri was cultured from pleural fluid. Two other patients carried group A betahaemolytic streptococci - in one case in pleural fluid and in the other case in blood. In the latter case influenza A virus was also definitely identified. In one patient blood cultures grew beta-haemolytic streptococcus group $\mathrm{C}$ and in another patient pleural fluid cultures yielded Streptococcus spp which was not typed further.

When we considered all patients together, regardless of the aetiological classification, $S$ pneumoniae remained the most frequent microorganism $(27 \%, 90 / 334)$, viruses and Haemophilus influenzae ranked second (8\%), and $M$ pneumoniae third (6\%). The prevalence of dual infections could, theoretically, only be properly estimated for patients in whom all diagnostic procedures (including serological tests) were performed; $25(10 \%)$ of the 239 cases who underwent serological testing were found to have a dual infection (table 3). Viral infections were present in 10 patients; in six $S$ pneumoniae was also detected.

\section{MORTALITY}

Twenty six patients (8\%) died in hospital. In 10 patients a pathogen was detected; $S$ pneumoniae was cultured from the blood in five, $S$ aureus in three, and Kpneumoniae in one. One patient had $E$ coli as the possible cause of pneumonia.

The relative risk of death for patients with a positive blood culture was $3 \cdot 4$ (95\% confidence interval 1.4 to 8.0 ). Age (Student's $t$ test, $\mathrm{p}<0.01)$ and a coexisting malignancy $\left(\chi^{2}\right.$, $\mathrm{p}<0.05)$ were also associated with a higher death rate (data not shown).

\section{Discussion}

The results of the present study show that a causative micro-organism could be detected in about half of the patients who require admission to hospital for community-acquired pneumonia, and that $S$ pneumoniae, $H$ influenzae, viruses, and $M$ pneumoniae together account for about $75 \%$ of these cases. The number of cases of pneumococcal bacteraemia (44) is high compared with other studies, ${ }^{4-10}$ probably because of the low percentage of cases receiving antibiotic treatment prior to admission. Haemophilus influenzae was never classified as a definite aetiological agent of community-acquired pneumonia, although invasive $H$ influenzae in patients with community-acquired pneumonia has been reported. ${ }^{11}$ However, we did not culture this micro-organism from blood or pleural fluid. Legionella pneumophila and Chlamydia spp were identified in nearly $10 \%$ of patients in whom serological tests were performed. The tests used to detect Chlamydia spp did not differentiate between $C$ pneumoniae and $C$ psittaci, and presumably most of the patients suffered from $C$ pneumoniae as a seroepidemiological study has shown that the prevalence of antibodies against $C$ pneumoniae is about $80 \%$ in the Netherlands. ${ }^{12}$ Moreover, a study in Norway has shown that the aetiology of community-acquired pneumonia first diagnosed as ornithosis was mainly due to $C$ pneumoniae. ${ }^{13}$ All patients with a blood culture revealing $S$ aureus died within two days of admission. Dual infections were present in about $10 \%$ of patients.

In $45 \%$ of all cases no aetiological agent for community-acquired pneumonia was found. Aetiological diagnosis can be hampered by lack of sputum production during the first 24 hours of admission, treatment with antibiotics before admission, or the fact that serological tests were not carried out because no second serum sample had been collected.

The inability to expectorate sputum generally occurs in about $30 \%$ of patients admitted to hospital with community-acquired pneumonia. ${ }^{14}$ In the present study $39 \%$ of patients, according to their clinical records, could not produce sputum during the first 24 hours of admission. However, we investigated the number of cases in whom failure to obtain a sputum specimen was the result of not taking care to collect it and found this to be the reason in 20 patients, in 14 of whom none of the other diagnostic tests revealed a micro-organism. For $50 \%$ of the 204 patients who produced sputum, according to their clinical records, cultures of these samples yielded a micro-organism. 
Table 4 Characteristics and results of four studies of community-acquired pneumonia

\begin{tabular}{|c|c|c|c|c|}
\hline & Marrie et al $^{8}$ & BTS study ${ }^{4}$ & Fang et $\mathrm{al}^{9}$ & Present study \\
\hline $\begin{array}{l}\text { Study period } \\
\text { No. of patients } \\
\text { Exclusion criteria }\end{array}$ & $\begin{array}{l}1981-7 \\
719[131] \dagger \\
\text { Prior hospitalisation within } \\
10 \text { days }\end{array}$ & $\begin{array}{l}1982-3 \\
453[-] \dagger \\
<15 \text { or }>75 \text { years } \\
\text { Pneumonia not main reason } \\
\text { for admission } \\
\text { Terminal pneumonia }\end{array}$ & $\begin{array}{l}1986-7 \\
359[46] \dagger \\
\text { Prior hospitalisation within } \\
1 \text { week }\end{array}$ & $\begin{array}{l}1991-3 \\
334 \text { [-] } \\
<18 \text { years } \\
\text { Prior hospitalisation within } 1 \text { week } \\
\text { Patients living in nursing home }\end{array}$ \\
\hline $\begin{array}{l}\text { Pre-admission antibiotics } \\
\text { Special tests for detecting }\end{array}$ & $\begin{array}{l}32 \% \\
C \text { pneumoniae }\end{array}$ & $\begin{array}{l}45 \% \\
\text { Pneumococcal antigens }\end{array}$ & $\begin{array}{l}19 \% \\
C \text { pneumoniae } \\
\text { Legionella spp }\end{array}$ & $\begin{array}{l}16 \% \\
\text { None }\end{array}$ \\
\hline $\begin{array}{l}\text { Pathogens (\% (95\% CI))* } \\
\text { S pneumoniae } \\
\text { M pneumoniae } \\
\text { H influenzae } \ddagger \\
\text { Chlamydia spp } \\
\text { Legionella spp } \\
\text { Viruses } \\
\text { Unknown }\end{array}$ & $\begin{aligned} 9 & (6 \text { to } 10) \\
6 & (4 \text { to } 8) \\
4 & (3 \text { to } 5) \\
6 & (4 \text { to } 8) \\
2 & (1 \text { to } 3) \\
8 & (6 \text { to } 10) \\
47 & (43 \text { to } 51)\end{aligned}$ & $\begin{array}{l}34(30 \text { to } 38) \\
18(14 \text { to } 22) \S \\
6(4 \text { to } 8) \\
3(1 \text { to } 5) \\
2(1 \text { to } 3) \\
7(5 \text { to } 9) \\
33(29 \text { to } 37)\end{array}$ & $\begin{aligned} 15 & (11 \text { to } 19) \\
2 & (1 \text { to } 3) \\
11 & (8 \text { to } 14) \\
6 & (4 \text { to } 8) \\
7 & (4 \text { to } 10) \\
\frac{33}{33} & (28 \text { to } 38)\end{aligned}$ & $\begin{aligned} 27 & (22 \text { to } 32) \\
6 & (3 \text { to } 9) \\
8 & (5 \text { to } 11) \\
3 & (1 \text { to } 5) \\
2 & (0 \text { to } 4) \\
8 & (5 \text { to } 11) \\
45 & (40 \text { to } 50)\end{aligned}$ \\
\hline
\end{tabular}

* Double infections included.

† Numbers in square brackets are those with a nursing home-acquired pneumonia.

$¥$ Only for three cases was this micro-organism considered a definite cause of community-acquired pneumonia.

Endemic year for $M$ pneumoniae.

Therefore, in only seven of the 14 patients might an aetiological diagnosis have been missed as a result of the lack of sputum collection in this study.

The use of antibiotics before admission will decrease the number of positive blood or sputum cultures. ${ }^{4}$ In 32 of the 54 patients who took antibiotics before admission no pathogens were detected. For patients who did not use an antibiotic before admission $(n=280)$ cultures yielded a micro-organism in $39 \%$. On the basis of these figures we can expect that for 12 of those 32 patients a pathogen would have been found had they not used an antibiotic before admission to hospital.

The percentage of cases detected by serological tests was $26 \%$. Thus, of the 52 patients with incomplete serological results and negative cultures one could expect at best 14 to have an infection with a micro-organism identifiable by serology. Probably this is an overestimation because most of the serologically proven cases in our study were pneumonias caused by $M$ pneumoniae which is commoner in young adults, ${ }^{1516}$ whereas most of the patients $(65 \%)$ in whom no serological test was performed were aged 60 years or older. When all of these factors are taken into account, resulting in "optimal" study conditions, no pathogen might have been detected in $35 \%(118 / 334)$ instead of $45 \%$ $(151 / 334)$ of the cases.

We compared the results of this study with other recent large studies. ${ }^{489}$ All used the presence of a new infiltrate on the chest radiograph for inclusion, but exclusion criteria differed (table 4). Differences in diagnostic methods are an important factor that can explain the varying results. In the British Thoracic Society study ${ }^{4}$ pneumococcal antigens were detected by countercurrent immunoelectrophoresis and, as a result, $S$ pneumoniae was diagnosed more frequently than in the other studies. ${ }^{489}$ The sensitivity and specificity of this test is still debated and further investigations need to be performed. ${ }^{17-19}$ In those studies in which special techniques were used to detect Chlamydia pneumoniae or Legionella spp, relatively high prevalences of the respective organisms were found. ${ }^{89}$
Seasonal, geographical, and endemic influences will affect the outcome of studies on community-acquired pneumonia. During the British Thoracic Society study there was an epidemic of $M$ pneumoniae, as clearly indicated by the results (table 4$).{ }^{1}$ During this study there was a threefold increase in the number of cases of $M$ pneumoniae in 1992 compared with 1991 (National Surveillance of Virological Laboratories, the Netherlands). However, we did not observe this increase as in both study years an equal number of $M$ pneumoniae was detected. Studies performed over a longer period of time should give more information about seasonal influences on the aetiology of communityacquired pneumonia. However, we did not find any seasonal effects during the 27 months of the study. Geographical differences, however, are probably important to a certain extent. The study by Marrie $e t a l^{8}$ performed in the region of Nova Scotia where $Q$ fever is endemic revealed that $3 \%$ of the cases of communityacquired pneumonia were caused by $C$ burnetti while, in other studies, less than $1 \%$ of the patients suffered from $Q$ fever. ${ }^{489}$

Updated knowledge of the prevalence of causative agents of community-acquired pneumonia in a distinct region, over a certain period of time, can help to determine the empirical antimicrobial treatment for this infection. A problem of great concern in the present study, as in other studies, is the relatively high percentage of unknown causes of communityacquired pneumonia. As explained above, this could be partly the result of a lack of "optimal" study conditions. Another cause could be the fact that we used only routine microbiological tests. The number of undetected pathogens will probably decrease when a wider range of better tests is used in epidemiological studies on community-acquired pneumonia. In the British Thoracic Society study ${ }^{4}$ it was shown that the finding of an aetiological diagnosis was correlated with the number of microbiological tests performed. Combining the results of the three studies discussed with our study, merely as a hypothetical situation, shows that, at best, an aetiological diagnosis can be made in $85 \%$ of the cases. 
This work was supported by a grant from Pfizer International Inc, New York.

1 Macfarlane JT. Community-acquired pneumonia. In: Mitchell DM, ed. Recent advances in respiratory medicine. Edinburgh: Churchill Livingstone, 1991:109-24.

2 Bakx JC, Bongers FJM, Bosch van den WJHM, Huygen FJA, Lagro HAHM, Lagro-Janssen ALM, et al. Ziekten van de tractus respiratorius. In: van de Lisdonk $\mathrm{EH}$, van den Bosch WJHM, Huygen FJA, Lagro-Janssen ALM, eds. Ziekten in de huisartspraktijk. Utrecht: Bunge, 1990: 189-91.

3 Garibaldi RA. Epidemiology of community-acquired respiratory tract infections in adults. $A m$ F Med 1985; 78(Suppl 6B):32-7.

4 Research Committee of the British Thoracic Society and Public Health Laboratory Service. Community-acquired pneumonia in adults in British hospitals in 1982-1983: a survey of aetiology, mortality, prognostic factors and outcome. $O \mathcal{7}$ Med 1987;62:195-220.

5 Macfarlane JT. Community-acquired pneumonia. $B r f D i s$ Chest 1987;81:116-27.

6 Centraal Bureau voor Statistiek. Gezondheid en maatschappelijk welzijn. Den Haag: SDU, 1994:479-518.

7 Sutherland JE, Persky VW, Brody JA. Proportionate mortality trends: 1950 through 1986. $\mathcal{F} A M A$ 1990;264:317884.

8 Marrie TJ, Durant H, Yates L. Community-acquired pneumonia. Rev Infect Dis 1989;11:586-99.
9 Fang G, Fine M, Orloff J, Arisumi D, Yu VL, Kapoor $\mathrm{W}$, et al. New and emerging etiologies for communityacquired pneumonia with implications for therapy. Medicine 1990;69:307-16.

10 Berntsson E, Blomberg J, Lagergard T, Trollfors B. Etiology of community-acquired pneumonia in patients requiring hospitalization. Eur f Clin Microbiol 1985;4:268-72.

11 Farley MM, Stephens DS, Brachman JPS, Harvey RC, Smith JD, Wenger JD, et al. Invasive Haemophilus influenzae disease in adults. Ann Intern Med 1993;116:80612.

12 Stolk-Engelaar MVM, Peeters MF. Heeft Chlamydia TWAR betekenis in Nederland. Ned Tijdschr Geneeskd 1990;134:1094-7.

13 Bruu A, Haukenes G, Aasen S, Grayston JT, Wang S, Klausen OG, et al. Chlamydia pneumoniae infections in Klausen OG, et al. Chlamydia pneumoniae infections in Infect Dis 1991;23:299-304.

14 Marrie TJ. Community-acquired pneumonia. Clin Infect Dis 1994;18:501-15.

15 Woodhead MA, Macfarlane JT. Comparative clinical and laboratory features of Legionella with pneumococcal and mycoplasma pneumonias. $B r f$ Dis Chest 1987;81:133-9.

16 Tuazon CU, Murray HW. Atypical pneumonias. In: Pennington JE, ed. Respiratory infections: diagnosis and management. New York: Raven Press, 1988:341-63.

17 Nouyen. NH York: Raven Press, 1988.341-63. Nguyen MH, Yu VL. Community-a Opin Infect Dis 1993;6:158-62.
Cur

18 Venkatesan P, Macfarlane JT. Editorial. Thorax 1992;47: 329-31.

19 Farrington M, Rubenstein D. Antigen detection in pneumococcal pneumonia. F Infect Dis 1991;23:109-16. 